\title{
Cardiac Stem Cell
}

National Cancer Institute

\section{Source}

National Cancer Institute. Cardiac Stem Cell. NCI Thesaurus. Code C124143.

Multipotent progenitor cells that are found in the fetal and adult heart that provide the

myocardium with limited regenerating capability. 